\title{
ANTIGUOS TEXTOS DE CIENCIA CONVERTIDOS EN POESÍA: DIOSCÓRIDES Y ANDRÉS DE LAGUNA EN EL LIBRO DE LOS VENENOS, DE ANTONIO GAMONEDA ${ }^{1}$
}

Francisco Garcia JURAdo

Universidad Complutense

\section{REsumen}

Puede parecer inesperado y excepcional, a simple vista, el hecho de que el poeta Antonio Gamoneda haya tomado los viejos textos de Dioscórides como inspiración poética. Sin embargo, distintos hechos, tales como la fascinación por el lenguaje, la bibliofilia, el amor por los autores antiguos, o el entusiasmo por la reescritura, explican esta recreación de un viejo texto de ciencia griego y lo sitúan dentro de una suerte de tradición que no es otra cosa que un buen ejemplo de lo complejas que pueden llegar a ser las relaciones entre la literatura clásica y las obras del s. XX.

1 Este trabajo se inscribe en el Proyecto de Investigación Universidad-MEC «Cultura Clásica y Renacimiento: Textos para la investigación interdisciplinar y el conocimiento de los fundamentos del mundo moderno*. Deseo expresar mi agradecimiento a Antonio Guzmán Guerra e Isabel Velázquez Soriano por su atención y observaciones a este trabajo. 
1. UN TEXTO MÉDICO GRIEGO TRADUCIDO POR UN HUMANISTA COMO SUSTANCIA LITERARIA: GAMONEDA Y EL DIOSCORIDES DE ANDRÉS DE LAGUNA

Resulta, cuanto menos, llamativo, el hecho de que uno de nuestros mejores poetas actuales se haya interesado por una obra como la traducción que el humanista segoviano Andrés de Laguna hiciera de La materia médica de Dioscórides, el médico griego del s. I, para tomar precisamente de ella inspiración poética. El que obras de la Antigüedad o del Humanismo se conviertan en motivos literarios susceptibles de reescritura no es un hecho nuevo ni mucho menos ajeno a los autores del $\mathbf{s}$. XX, al menos dentro de un tipo de literatura de carácter erudito donde podemos ver asomarse, al calor de la lectura, el texto de un autor griego, latino, medieval o renacentista, con independencia del género de obra que estemos leyendo y del género que el autor antiguo cultivara. A simple vista, parece impensable que un tratado médico pueda servir de inspiración poética. Tenemos que recordar, no obstante, que los textos que en el pasado sirvieron de fuente para el conocimiento hoy día se ven reducidos a la condición de viejos testimonios del saber en épocas pasadas. En este sentido, bien podemos aplicar las siguientes palabras de Borges acerca de Plinio el Viejo ${ }^{2}$ a la «corrupción» que el poeta Antonio Gamoneda ${ }^{3}$, asturiano de nacimiento (Oviedo, 1931) y leonés de residencia, hace de los textos médicos de Dioscórides traducidos y comentados por Andrés de Laguna: «Épocas hubo en que se leían las páginas de Plinio en busca de precisiones; hoy las leemos en busca de maravillas, y ese cambio no ha vulnerado la fortuna de Plinio». Gamoneda ha llevado a cabo una reescritura del libro sexto de La materia Médi$c a$, a la que el poeta ha añadido, además, sus propios apuntes, que no son otros que los de Plinio, o Plutarco, cúmulo de conocimientos perdidos que se aderezan, asimismo, con pasajes líricos y otras ficciones diversas.

Así las cosas, el propósito de nuestro trabajo es el estudio de las circunstancias que dan lugar, precisamente, a esta reescritura de un texto médico por parte de un poeta. Atendemos a varios aspectos, tales como la importancia del léxico (2.), el papel del lector en la reescritura y el género de la obra (3.), el juego tipográfico y la estructura (4.) y, finalmente, la relación del Libro de los venenos con la obra anterior de Gamoneda (5.).

2 BORGES, JORGE LUIS (1975): «Edward Gibbon: páginas de historia y de autobiografia», en Prólogos con un prólogo de prólogos (citado por Obras Completas, tomo IV, Barcelona, Emecé, 1996, p. 71).

${ }^{3}$ Gamoneda, Antonio (1995): Libro de los venenos. Corrupción y fábula del Libro Sexto de Pedacio Dioscórides y Andrés de Laguna, acerca de los venenos mortíferos y de las fieras que arrojan de si ponzoña, Madrid, Siruela (colección «La Biblioteca Sumergida»). A partir de ahora, para referimos a este libro lo haremos simplemente con GAMONEDA. 


\section{LA «SOBERANIA DE LAS PALABRAS»}

Uno de los motivos fundamentales que ha llevado a Gamoneda a la reescritura del Dioscórides de Laguna ha sido, precisamente, el de la sonoridad y la fuerza etimologica de las palabras, lo que, por lo demás, ha supuesto desde antiguo una fuente de creación artística. Gamoneda, autor preocupado por el caudal léxico, se ha sentido primeramente atraído por la belleza de los términos de plantas, animales y venenos, además de la buena prosa de Andrés de Laguna $^{4}$, y así nos lo declara el mismo poeta ${ }^{5}$ :

(G) Por lo que concierne a la versión de Laguna, las copıosas anotaciones que añade están enriquecidas por su cumplida condición de humanista (traductor numeroso de Aristóteles y Galeno), pero a mí, dicho sea a pecho abierto, poco se me da de estas sabidurías del segoviano, que me tiene cogido y hasta cegado por la soberanía de las palabras, con lo que, pidiendo ser perdonado, digo que no me importa otra verdad o mentira que el resplandor de la obra en dichas palabras, y que a éste sirvo sin miramientos, de modo que entro en cirugía lingüística cuando me parece que Laguna se pone enfadoso (...) (GAMONEDA, pp. 12-13).

A esta hermosa prosa de la traducción y las anotaciones de Andrés de Laguna hay que añadir, además, la belleza que tienen ya per se los distintos términos de venenos, tales como la «amphisbena», el «dryno», o el «psilio». Precisamente, en el capítulo dedicado al «psilio» podemos encontrar como muestra este resonante texto:

(G) Y cuenta que Muda, en quien obraba el psilio, pedía amor a Látide con lengua torpe y crecida dentro de la boca, y que, habiendo entrado en la celda para examinar los cuerpos, pudo sentir que en Látide latían veloces los hipocondrios (GAMONEDA, p. 58).

A la creatividad de las palabras o, en feliz expresión de José MÉNDEZ ${ }^{6}$, «ebriedad del lenguaje», contribuyen, asimismo, las etimologías de Andrés de

4 Para la relevancia del léxico en la obra de Andrés de Laguna, cf. el trabajo de Manuel ALVAR, «Las anotaciones del doctor Laguna y su sentido lexicográfico», pp. 13-54, en el volumen de estudios anejo a la edición facsímil del Dioscbrides que aparece citada en la nota 14.

5 Dado que, como explicaremos más adelante, el texto del Libro de los venenos está escrito a tres voces, a saber: la de Dioscórides (D), Laguna (L) y Gamoneda (G), precisaremos al comienzo de las citas que hagamos del libro la voz de aquel que habla.

- «Un libro para aquellos que gusten de perderse, de sentir por encima de significados, por encima incluso del significado concreto de palabras concretas, la ebriedad del lenguaje. El lengua- 
Laguna, como la del «tóxico» (GAMONEDA, p.72), o la de la «amphisbena», de la que reproducimos este fragmento que gira precisamente en torno a la interpretación de amphi- («por ambos lados»):

(L) Se dice que la amphisbena está dotada con dos cabezas, de lo cual se persuadieron algunos porque, la que tiene, en dobles partes es igualmente abultada, como la sanguijuela, y porque hacia entrambas partes camina.

(G) Por mano de san Isidoro ${ }^{7}$ está escrito que, de sus dos cabezas, la amphisbena tiene una en la cola, lo cual es disparate canónico (GAMONEDA, p. 138).

Para dar justificada cuenta de esta fascinación por las palabras, nos permitimos recurrir a un texto del escritor catalán Joan PERUCHO, interesado asimismo por la erudición y las letras antiguas, que nos ilustra de esta manera:

El primer día de la Creación dio a las cosas una naturaleza específica, tal como estaban en la idea de Dios. Eran, recién estrenadas, prístinas y recortadas, con una morfología concreta y sorprendente. El hombre las puso nombre. En el mundo de la Botánica, por ejemplo, inventó los de abrótano, brionia, camelia, damiana, enebro, fresera, gatuña, heliotropo, iris, jacinto, lirio, melisa, narciso, olivo, palmera, ricino, sáuco, tamarindo, valeriana, yedra y zaragatona. Todo, efectivamente, por orden alfabético. Lo mismo podríamos decir de las piedras, las aguas y los animales con sus encantos y virtudes primigenias. (...) Todo esto ha desaparecido. Las cosas han evaporado su mística naturaleza transformándose en largos y tristes nomenclátors (sic) racionalistas. Nadie sabe ya el nombre de los pajaros o de las hierbas. Es triste ${ }^{8}$.

je como saliva, como hálito primordial, como salvación no de la ignorancia o la comunicación, sino de la presencia de los seres, reales o imaginarios, de virtudes o defectos también reales o imaginarios. Un libro en la frontera del tiempo. Atemporal. Un libro de poesía incontaminada, producida no sólo por la sedimentación producto de los siglos, sino gestado desde la palabra poética, la ciencia primigenia, el apuntar posibilidades entrevisto en la facultad de nombrar» (Reseña al Libro de los Venenos, ABC Literario, 3-XI-95). A su vez, GARCtA GuAL sefiala este mismo hecho en la reseña que dedic6 a este libro en El País del 4-XI-95: «Para el lector de ciudad, nada ducho en plantas y poco habituado a tratar con los humildes y fragantes brotes de los campos, muchos nombres serán sólo referencias a un mundo de ya lejanos aromas y colores. Y la doctrina aqui expuesta será revelación de un mundo botánico misterioso, y de extraña poética, que fue antańo familiar. Los nombres de origen helénico alternan con los términos castellanos clásicos (...)m.

7 Amphisbaena dicta, eo quod duo capita habeat, unum in loco suo, alterum in cauda, currens ex utroque capite, tractu corporis circulato (Isid. Orig. 12,420).

- PERUCHO, JoAn (1995): «Sentido de la creación», en La puerta cerrada, Madrid, Huerga \& Fierro, pp. 47-48. 
De esta forma, merced a la belleza del caudal léxico y de la prosa de Laguna, podemos disponer ya del principal criterio de inspiración para el poeta. Los motivos, sin embargo, no se agotan aquí.

\section{El GÉNERo y El LECTOR. LA REESCRITURA}

Otro aspecto pertinente de la obra de Gamoneda es el hecho significativo de que el libro comience precisamente hablando del lector, a quien encomienda la tarea nada fácil de decidir acerca del género de la obra"

(G) El lector de este Libro de los venenos tendrá que decidir por sí mismo la especie de la obra que tiene en sus manos (GAMONEDA p. 11).

Como el mismo poeta reconoce, puede pensarse que se trata de un tratado científico de la Antigüedad vertido a la prosa castellana y comentado en el Renacimiento y, una vez más, enriquecido ahora con nuevas notas. Por otra parte puede verse en él un cuerpo narrativo cuyos principales personajes son el médico Cratevas y el rey Mitrídates del Ponto. Y a todo esto puede sumarse, siempre según el propio Gamoneda, algunas divagaciones líricas. En todo caso, el autor no tiene intención alguna de declarar el género posible de la obra ${ }^{10}$ :

(G) Yo no puedo resolver por cuenta del afectuoso lector: estoy perfectamente instalado en la confusión, no me interesa poco ni mucho la clasificación en géneros de la escritura y lo único que he logrado distinguir (y gozar) como razón de mi trabajo es la energía poética del lenguaje (la de Dioscórides, la de Laguna y, con mayores esfuerzos, la mía propia), de modo que, convencido de que los llamados generos no son otra cosa que poesía diversamente preparada, me retiro del problema (GAMONEDA, p. 11).

El texto de Gamoneda es, fundamentalmente, el producto de una lectura. El mismo es lector que media entre los textos que le sirven de fuente y sus pro-

9 Vienen al caso estas palabras de Gérard Genette al respecto: «En todos los casos, el texto en sí mismo no está obligado a conocer, y mucho menos a declarar, su cualidad genérica» (GENETTE, GÉRARd [1989]: Palimpsestos. La literatura en segundo grado, Madrid, Taurus, p. 13).

10 Garcia Gual comenta de esta manera en su reseña ya citada la actitud del poeta: «Queda abierta la cuestión de a qué género literario pertenece este libro a tres voces. Gamoneda, un tanto irónico, no da solución al problemaw. 
pios lectores, y en alguna ocasión da muestras de su lectura previa anticipándose a lo que después dirán Dioscórides y Laguna ${ }^{11}$. El texto original ha sido «reescrito», o como el mismo Gamoneda prefiere decir, «corrompido», despreciando en este punto las ideas de originalidad (GAMONEDA, p. 13). Gamoneda ha seccionado el texto de Dioscórides y Laguna donde ha creído conveniente, alterando de formas diversas el pasaje seleccionado. Podemos tomar como muestra el comienzo de la obra, donde hemos adoptado las convenciones de un aparato crítico para poder apreciar con más comodidad las variantes que el poeta introduce sobre el texto original que ha asumido como propio ${ }^{12}$ :

\section{Prefacio}

En este libro', que será el último de nuestra ${ }^{2}$ fatiga, tratare ${ }^{3}$ de la facultad y fuerza de los venenos y de los remedios saludables contra ellos. Diré prime$\mathrm{ro}^{4}$ del modo preservativo, el cual tuvieron los antiguos 5 por muy difícil a causa de que los que quieren dar secretamente veneno despojan de su natural amargor a las substancias mortiferas ${ }^{6}$ y les quitan su hediondez con gomas aromáticas'. También las mezclan ${ }^{8}$ con aquellas medicinas que suelen darse para conservar la salud y las deslíen ${ }^{9}$ en las purgas o las esconden en el interior de las ${ }^{10}$ viandas. Por ello ${ }^{11}$, los que viven con temor y sospecha deben huir de los guisados exquisitos ${ }^{12}$ y no beber ${ }^{13}$ ni comer arrebatadamente sin gustar primero en lo más sutil ${ }^{14}$ el sabor de aquello que beben y comen.

Ésta es, pues ${ }^{15}$, la vía y manera para que ${ }^{16}$ los hombres no se dejen atosigar, aunque hay otra cautela mucho más efica ${ }^{17}$ : que quienes recelen ${ }^{18}$ ser ayudados en el negocio mortal ${ }^{19}$ tomen causa ${ }^{20}$ preservativa que debilite la fuerza de los venenos y los haga impotentes, para lo cual ${ }^{21}$ sirven los higos secos y la simiente de los nabos ${ }^{22}$. Resisten así mismo contra el veneno las hojas de la nepeta y la tierra llamada lemnia, tomándose de la una o de la otra ${ }^{23}$ una dracma hervida $^{24}$ con vino. Los que coman ${ }^{25}$ en ayunas las hojas de la ruda con el meollo de una nuez y, juntamente, dos higos y un grano de sal no serán nunca ${ }^{26}$ ofendidos. Las medicinas llamadas antídotos tienen esta ${ }^{27}$ misma fuerza, y así son $^{28}$ las que se hacen del scinco y de $1 a^{29}$ sangre, $1 a^{30}$ que tienen metridato ${ }^{31}$ por nombre y la desconocida triaca ${ }^{32}$. Hay también ${ }^{33}$ complexiones de cuerpos que resisten naturalmente a cualquier veneno $\mathrm{y}$, así mismo, algunas disposiciones,

1 «Del dryno dan seffas más adelante Dioscórides y Laguna» (GAMONEDA, p. 30).

${ }^{12}$ Las notas voladas que aparecen en el texto de Gamoneda responden a las variantes que éste ha introducido a partir del texto seleccionado de la traducción de Andrés de Laguna. 
engendradas de cualidades ${ }^{34}$ de aquellas cosas que se comen y beben, que $\mathrm{e}^{35} \mathrm{em}$ botan y resuelven su malignidad ${ }^{36}$ y le impiden derramarse por todo el cuerpo.

L: Laguna G: Gamoneda

${ }^{1}$ En este libro: en el presente $L 5 \quad{ }^{2}$ de nuestra: de toda nuestra $L 6 \quad{ }^{3}$ trataré: trataremos $L 6 \quad{ }^{4}$ Dire primero: diremos primeramente $L 11$ '5antiguos: ancianos $L 11-12$ 'substancias mortíferas: venenos mortiferos $L 14 \quad{ }^{7}$ gomas aromáticas: cosas aromaticas, y odoriferas $L 15 \quad{ }^{8}$ También las mezclan: Mezclanlos también $L 15$ 'y las deslíen: desleydos $L 21$ "las esconden en el interior de las: amassados con algunas $L 21-22$ "Por ello: Por donde $L 22 \quad{ }^{12} \mathrm{De}$ los guisados exquisitos: todo guisado exquisito $L 22 \quad{ }^{13} \mathrm{y}$ no beber: no deven bever de golpe $L$ 24-25 ${ }^{14}$ sin gustar primero en lo más sutil: sin primero gustar y sentir $L 25$ iśsta es, pues: Aquesta pues es $L 31 \quad{ }^{16}$ para que: para que incautamente $L 31 \quad{ }^{17}$ cautela mucho más eficaz: mucho más efficaz y mejor cautela $L$ $32 \quad{ }^{18}$ que quienes recelen: que los que se recelan de $L 33 \quad{ }^{19} \mathrm{en}$ el negocio mortal: con algun bocadillo $L 33 \quad{ }^{20}$ causa: alguna $\operatorname{cosa} L 33 \quad{ }^{21}$ para lo cual: para el cual effecto $L$ $34 \quad{ }^{22}$ y la simiente de nabos: y una drama de la simiente de nabos $L 35 \quad{ }^{23}$ otra: otra cosa $L 37 \quad{ }^{24}$ hervida add. $G \quad{ }^{25}$ coman: comieren $L 37 \quad{ }^{26}$ serán nunca:seran $L 39$ ${ }^{27}$ esta: la $L 40 \quad{ }^{28}$ y así son: entre las cuales se cuentan $L 40 \quad{ }^{29} \mathrm{de}$ la: de $L 41 \quad{ }^{30} \mathrm{la}$ : y la $L 41 \quad{ }^{31}$ metridato: gran Metridato $L 41 \quad{ }^{32} \mathrm{y}$ la desconocida triaca add. $G \quad{ }^{33} \mathrm{Hay}$ también: Hallanse muchas vezes ciertas $L 41-42{ }^{34}$ de cualidades: de ciertas qualidades $L 43 \quad{ }^{35}$ que: las quales cosas $L 44 \quad{ }^{36}$ su malignidad: la malignidad del veneno $L 45$

Gamoneda ha suprimido partes enteras del texto original (véase, al final del artículo, la reproducción facsímil del texto de Laguna), y aquel que selecciona no se libra de la transformación, bien morfológica («coman», en lugar de «comieren»), o léxica («en el negocio mortal», en vez de «con algun bocadillo»), el cambio del orden de palabras («cautela mucho más eficaz», en lugar de «mucho mas efficaz y mejor cautela»), o incluso adiciones. De esta forma, el texto original de Andrés de Laguna queda tamizado por la lectura y reescritura de Gamoneda, quien, por encima de las convenciones de originalidad al uso, lo hace suyo.

4. Bibliofilia y JUEGo TIPOGRÁfico. Estructura de LA OBRA

No sólo la belleza del lenguaje contenido en el libro, sino el mismo libro, como soporte singular, despierta la admiración de Gamoneda. Se trata, pues, de una obra de poeta y, a su vez, de amante de los libros antiguos ${ }^{13}$. El texto, por

13 Así lo declaraba el propio Antonio Gamoneda en una entrevista concedida al programa «El ojo crítico", de RNE (21-IX-95). 
lo que podemos colegir en la «Noticia» inicial que abre la obra, ha sido probablemente tomado de la primorosa ${ }^{14}$ edición de Amberes publicada en 1555 , circunstancia a la que se refiere el propio Gamoneda ${ }^{15}$. Es importante hacer ver que este hecho no parece ser ni accesorio ni casual. Como podemos comprobar a simple vista, se ha conservado la disposición tipográfica del original, a saber, en letra redonda el texto traducido de Dioscórides, y en cursiva el comentario de Andrés de Laguna. El poeta no se ha conformado con la «corrupción» de los textos de que parte, sino que, además, ha añadido, ahora en una redonda en cuerpo menor, diversos comentarios extraídos, a su vez, de nuevos autores, o bien fabulaciones. Así las cosas, el libro de Gamoneda se sustenta sobre el juego intertextual de los textos de DIOSCÓRIDES (D), los comentarios de LAGUNA (L) y de aquellos textos citados o inventados que englobamos bajo el epígrafe general de GAMONEDA (G). De esta forma, el Prefacio de la obra, que en la edición original de Amberes es simplemente el prefacio de Dioscórides seguido por el comentario de Laguna (D L), se articula, en este caso, con una alternancia reiterada entre el texto de Dioscórides y el de $\mathrm{Ga}$ moneda, para cambiar después a una nueva alternancia entre Laguna y Gamoneda (D G D G D G L G L G L G L G L G L G L G L G L G). A continuación, pasamos a la lectura de los capítulos dedicados a distintos venenos, que se abren siempre con el texto de Dioscórides, a lo que suele seguirle un comentario de Gamoneda, y después pasar al texto de Laguna, seguido, asimismo, de un nuevo comentario de Gamoneda (DGLG 22 veces). Otra estructura también recurrente es aquella en la que al texto de Dioscórides le sigue el comentario de Laguna, entrando, finalmente, el texto de Gamoneda para cerrar el capítulo (DLG 13 veces):

14 Dioscbrides. Materia médica y venenos mortfferos. Traducido e ilustrado por el doctor Andrés de Laguna, Amberes, 1555. Hemos utilizado la edición facsímile de la Consejería de Agricultura y Cooperación de la Comunidad de Madrid, editada en 1991 (Cf. Reseña de Garcla GuAL, en El Pats, 13-VI-92). Se trata de una edición primorosa tanto en su aspecto material como en su calidad filológica (Cf. GUZMAN GUERRA, ANTONIo [1978]: El Dioscórides de Laguna y el manuscrito de Pérez de Castro, Madrid, UCM, pp.15-16).

15 «El Dioscórides de Andrés de Laguna se imprimió en Amberes (1555), y, después de su muerte, en Salamanca» (GAMONEDA, p. 13). 


\section{DGLG DLG OTRAS COMBINACIONES}

DE LAS CANTÁRIDAS D GLG

DE LAS ORUGAS

$\begin{array}{ll}\text { DE LOS BUPRESTES } & \text { D G L G } \\ \text { DE LA SALAMANDRA } & \text { D G L G }\end{array}$

DEL EPHEMERO

D G L G

DEL DORYCNIO

DEL ACÓNITO

DE LA MIEL

DEL CULANTRO

DEL PSILIO

DE LA CICUTA

DEL TEJO

DEL LICOR

DE LA YERBA

DEL HYOSCYAMO

DGLG

DE LA MANDRÁGORA D G L G

DEL LICOR

DEL PHÁRICO

DGLG

DGLG

DEL TOXICO

DE LA IXIA

$D G L G$

DGLG

DE LA CERUSA

DE LOS HONGOS

DEL YESO

DE LA SANGRE

DE LA LECHE

DEL LITHARGIRIO

DEL AZOGUE

DE LA CAL

DE LA LIEBRE

DE LA RANA

DE LAS SANGUUJUELAS

DEL ELEBORO

DE COSAS

DE LAS FIERAS

DE LAS SEÑALES

DE LOS REMEDIOS

DEL REGIMIENTO

DE LOS PHALANGIOS

DE LA ESCOLOPENDRA

DEL ALACRÁN

DE LA PASTINACA

DEL MUSGAÑo

DE LA VIBORA

DE LA AMPHISBENA

DEL DRYNO

D G L G

D L G

D

D G L G

DLG

D L G

D L G

DLG

D G

DL

DLG

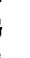




\begin{tabular}{|c|c|c|}
\hline DEL HYDRO & & \\
\hline DEL CENCRO & D G L G & \\
\hline DEL CERASTE & & \\
\hline DEL ÁSPID & D G L G & \\
\hline DEL BASILISCO & & DLGLG \\
\hline DE LA CURA & & DGDGDGDGLGLGLGLGL \\
\hline FIN & & L \\
\hline
\end{tabular}

Se puede rastrear, de esta forma, cierta intención de recurrencia y, además, respeto a la antigua jerarquización ${ }^{16}$ de los textos, de forma que el texto de Dioscórides siempre aparece al comienzo de cada capítulo y jamás sirve de comentario a los otros. Gamoneda señala, asimismo, otras posibilidades de combinación de textos que no ha explotado: «Al cabo ya de mi trabajo, me pesa no haber ido a la profundidad de los libros de Piero Andrea Mathiolo, médico en Siena y en Trento, porque sus comentarios de Dioscórides no se acobardan, al parecer, ante los de Laguna. Pero ya no es tiempo» (GAMONEDA, p. 165). Por lo demás, los capítulos de la edición de Laguna coinciden, salvo algún pequeño detalle y, en especial, exceptuando la ausencia de los capítulos finales, con los que recoge Gamoneda en su libro.

A todo este esmero tipográfico y respeto a la belleza original del libro de Laguna, queremos añadir, asimismo, un esbozo de «novela de bibliofilo» que está íntimamente unido a lo visto hasta aquí. Gamoneda atribuye ya desde el principio un halo misterioso al códice del médico Dioscórides, en especial a todo lo relativo a su libro VI:

(G) Dioscórides (Anazarba, Cilicia, cerca de Tarso, siglo I), recogiendo conocimientos en su coetáneo Plinio y en su antecesor Kratevas (autor éste de un Léxico botánico, de un Tratado de los simples y de otros escritos cuya existencia defiendo), ordenó uno que hoy sería compendio farmacológico; el códice constaba de cinco «libros», según los hermeneutas rigurosos, con lo cual empieza ya el misterio del libro sexto, que es el de la completa doctrina sobre los venenos y el asunto que aquí interesa (GAMONEDA, p. 12).

${ }^{16} \mathrm{EJ}$ concepto de jerarquización resulta fundamental a la hora de estudiar la inclusión y relación intertextual de los textos antiguos en obras modemas y contemporáneas. Cf. GARCta JURADO, FRANCISCO y LóPEZ GREGORIS, Rosario (1996): «Referencias explícitas a los autores clísicos en la novela histórica: entre el texto, la cita y el paratextow, XI Simposio de la Sociedad Española de Literatura General y Comparada (Madrid, diciembre de 1996). 
Pero son, ante todo, los códices de Cratevas ${ }^{17}$ (transcrito como «Kratevas» en el libro de Gamoneda) que parecen guardarse en la Biblioteca Secreta del Vaticano, lo que nos introduce ya de lleno en la ficción de los escritos desaparecidos, añadiendo, a su vez, las perdidas memorias de Mitrídates ${ }^{18}$ :

(G) Kratevas fue, quizá, el padre verdadero del antídoto metridato $y$, con seguridad, el creador de la inmunidad de Mitrídates. Esta seguridad se funda en el literal del códice existente en la Biblioteca Secreta del Vaticano, que relata las experiencias con venenos realizadas por Kratevas siguiendo las más de las veces órdenes de Mitrídates. Este códice, con el Léxico Botánico, que se guarda en la Biblioteca de París, y con el Tratado de los Simples, que se custodia en la Librería de Viena, podría ser toda la obra que dejó Kratevas. Estas escrituras debieron de pasar a manos de Pompeyo (con las memorias del propio Mitrídates, que hemos de dar por perdidas) cuando, vencido el Eupátor y voluntariamente yugulado por la obediencia de un servidor gálata, ya que, dicho está, Mitrídates se había privado a sí mismo de alcanzar la muerte mediante veneno, Kratevas paso al servicio del romano. Del texto que se guarda en la fundación de Nicolás $\mathrm{V}$, yo, dividido en mi amor por la fábula y la ciencia, tomo aquellas historias que iluminan el arte de procurar y recibir la muerte, y con ellas soy parte en el Libro Sexto de Dioscórides y Laguna (GAMONEDA, p. 37).

Las referencias al misterioso códice de Cratevas siguen apareciendo, como si de un leit-motiv se tratara, a lo largo de la lectura:

17 Los pocos fragmentos conservados de Cratevas pueden verse en Pedanii Dioscuridis Anazarbei De materia medica libri quinque, edidit Max Wellmann, tomo III, Berlín, Weidmann, 1958 , pp. 139-148.

18 Como es sabido, el género de las memorias perdidas como pretexto para fabular acerca de un personaje de la Antiguiedad es un recurso fecundo. Sabemos de estas memorias gracias a Plutarco, que en su vida de Pompeyo (Pomp. 37) nos dice asi: «En la fortaleza de Quenon vinieron a las manos de Pompeyo los papeles reservados de Mitrídates, y los examino con gemoria, y en ellos daban a conocer de un modo muy decisivo sus costumbres. Eran sus libros de mijo Ariarates, y a Alceo cubri6 que había dado muerte con hierbas, además de otros varios, a su hijo Ariaras Vidas paralelas Sardis, porque en una carrera de caballos le sacó ventajas" (PLUTARCO [1921]: [Agesilao, Pompeyo, Alejandro, César], tomo VII, trad. de A. RANZ Romantud p. 118). Debemos citar, por su proximidad temática, las memorias que P. MORAux publico hace unos años acerca del médico Galeno (Galien de Pergame. Souvenirs d' un médecin, Paris, «Les Belles Lettres», 1985). «Bajo la ficción de que Galeno es el autor, nos encontramos ante un relato biográfico rigurosamente documental, ya que los fragmentos de las memorias, agrupados no según cronología estricta, pero sí según un orden logico, proceden del corpus galénico» (reseña de M." Jesús Pérez IbÁÑez en Minerva 3, 1989, pp. 338-339). 
(G) Aquí averiguo yo que Laguna no conocio, a pesar de sus dias vaticanos, el manuscrito de Kratevas, pues considera veloz al ephémero matando en veinticuatro horas y el códice atestigua que lo hace en menos de seis (GAMONEDA, p. 52).

(G) pero algo hay en esta ilustración de Laguna, que concierta con el códice de la Secreta (...) (GAMONEDA, p. 90).

(G) El códice de Kratevas debió de guardarse secreto muchos anfos a causa de obras que habrian de estar ocultas siendo sus autores vivientes (GAMONEDA, p. 138).

Asimismo, Gamoneda nos transmite la noticia rigurosamente histórica de la traducción al latín que Pompeyo Leneo (Pompeius Lenaeus), liberto de Pompeyo Magno, hizo de la obra de Cratevas, una vez vencido Mitrídates por aquél ${ }^{19}$ :

(G) Kratevas, cuyos códices conocemos puestos en latín por Pompeyo Leaneo (sic), gramático de Pompeyo el Grande, tenía su voluntad semejante en la diversidad a las fuerzas que habian dado forma a su vida, de modo que en $t$ l cabe encontrar un sentimiento piadoso en la vigilancia de la actividad, color, figura, intimidad y potencias de un ser hallado vivo, ya sea raiz de olor o sierpe dormida, y también una frialdad asiática a la hora de observar el pulso de los torturados. Aborrecía, no obstante, la suciedad y nadie vio nunca ensangrentadas sus manos o su túnica. Así resulta el hombre, según las disposiciones de la naturaleza y la sujeción a las necesidades propias y los deseos de los poderosos (GAMONEDA, p. 101).

Laguna da, por su parte, esta curiosa información acerca de cartas venenosas, sumándose así, involuntariamente, a la serie de comentarios sorprendentes acerca de impresos que venimos viendo:

(L) Tambien suelen hacer los turcos, de rejalgar y de otros venenos graves, una suerte de tinta tan maligna y perniciosa que escrita una

19 FUNAlOU, Hyoinus (1969): Grammaticae Romanae Fragmenta, Stuttgart, Teubner, (1' ed.1907), pp. 403-404. Cf. Plin. Nat. 25,5 antea condiderat solus apud nos, quod equidem inueniam, Pompeius Lenaeus Magni libertus, quo primum tempore hanc scientiam ad nostros perwenisse animo aduerto. namque Mithridates -singula exquirens scrinium commentationum harum et exemplaria effectusque in arcanis suis reliquit. Pompeius autem omni praeda regia potitus transferre ea sermone nostro libertum suum Lenaeum grammaticae artis iussit, uitaeque ita profuit non minus quam reipublicae uictoria illa. 
carta con ella y leída sin anteojos inficiona y derriba luego al lector, de lo cual no debemos maravillamos, pues los libros recién impresos nos dan vahídos de cabeza y debilitan la vista, de donde se puede colegir que la vista no se forma derramándose a fuera los rayos visuales por nuestros ojos, sino recibiendo por ellos en el cerebro las especies vivíficas (GAMONEDA, p. 31).

Pero Cratevas y Leneo no son más que dos autores de los que Gamoneda ha sabido gracias a otras fuentes, en especial las de Plinio el Viejo y Plutarco. Precisamente, las fuentes van a ocupar un lugar relevante en la construcción de la obra. La «Noticia» que abre el libro nos anticipa que va a declarar las mismas:

(G) No ocultare, sin embargo, la declaración de las fuentes y los extravíos concertados hasta ultimar el presente literal del Libro de los venenos (GAMONEDA, p. 12).

Tras una digresión, Gamoneda vuelve a declarar su intención de revelar las fuentes:

(G) Pero he prometido declarar las fuentes además de los extravios (GAMONEDA, p. 12).

Y termina, finalmente, por hacerlo ${ }^{20}$ :

(G) Por puro vicio (hay nombres que son como frutos en la boca), voy a escribir aquí todos los autores principales que recuerde. Lo hago sin orden ni concierto. Asf, Plinio (el primero entre sus iguales), Hipocrates (inolvidable cuando habla de kenfermedad sagradaw), Nicandro (cuyos poemas Teriaca y Alexifármaca me proporcionaron ánimo transgresor), Galeno (que trata precisamente de los antidotos), Teofrasto (muy aprovechable en relación con las plantas), Aristoteles (prodigioso sobre la vida, la sensación, la respiración, la muerte, la generación y la corrupción), Plutarco (que cuenta de Mitridates), Asclepíades (que entendía del pulso) y el majestuoso Virgilio. De la parte

No podemos entrar en la ingente labor de rastreo de todas las fuentes aludidas en el texto. Por otra purte, tan pertinente como la fuente es conocer la edición o traducción concreta que Antonio Gamoneda ha utilizado para scceder a los textos. Tal es el caso, por ejemplo, del Macer Floridus, donde hemos de suponer que ha utilizedo la traducción de PEDRo CABELLO DE LA TORRE y el prociono facsímil editudo por la Catedra de San Isidoro y la Universidad de Lón en 1990. 
oriental, Avicena y el anónimo hispano-árabe Umadt-al-Tabib; medievales, las Etimologias, de Isidoro, y el Lapidario de Alfonso X, más algún retal de Bernardo Gordonio y el poético y un tanto destartalado Macer Floridus. Sobre animales ponzoñosos, tomé del imprescindible Claudio Eliano, del Physiologo Griego y del Bestiario de Cambridge (GAMONEDA, p. 14).

Como lectores interesados por el uso literario de la erudición, podemos preguntarnos por qué tiene Gamoneda esa necesidad, prometida ya casi desde el principio de la «Noticia» y desarrollada plenamente al final de la misma, de declarar sus fuentes y no reducirlas al espacio marginal de una nota. Tales fuentes son seguramente irreconocibles para un lector moderno, en cuyo bagaje cultural no deben de estar posiblemente casi ninguno de los nombres citados. Un hecho que no puede perderse de vista es el del carácter técnico de casi todos los autores que aquí podemos encontrar. Los autores técnicos pueden convertirse, en efecto, en materia literaria, y este hecho no es ni sorprendente ni nuevo ${ }^{21}$. En la declaración explícita de fuentes puede haber, además, una reivindicacion sentimental de saberes olvidados.

\section{GAMONEDA Y EL LiBRO DE LOS VENENOS}

Nos queda, para terminar, una cuestión que afecta directamente al poeta, como es la relación de este Libro de los venenos con el resto de su obra anterior. Esta cuestion sale en parte fuera del objetivo de nuestro trabajo, y no podemos más que esbozarla aquí, ya a modo de conclusión. Quien conozca la obra poética de Gamoneda 22 no podrá dejar de sentirse en principio sorprendido ante las características del Libro de los venenos. Hemos tratado de explicar las razones que han podido moverle a una reescritura semejante, tales como la «soberanía de las palabras» y ver, a su vez, algunas de las características de tal reescritura, como son la disposición tipográfica y la indefinición intencionada del género. Pues bien, la reescritura no es un fenómeno nuevo en Gamoneda. Siguiendo a Miguel Casado, sabemos que Gamoneda es amigo de reescribir

${ }^{21}$ Cf. Garcfa Jurado, Francisco (1996): «La literatura latina como motivo (meta)literario explícito en la literatura del s.XX. Las variedades de su contextualización", en ANA M." ALDAMA (ed.), De Roma al siglo XX, tomo I, Madrid, UNED, pp.285-6.

22 Disponemos de la excelente recopilación de su obra poética en el volumen editado por CASADO, Miguel (1988): Edad, Madrid, Cátedra. La recopilación, por lo demás, lleva el título de uno de los libros más importantes del poeta. 
tanto su propia obra ${ }^{23}$ como la ajena. Este es el caso de su reescritura del «Llanto por la muerte de Ignacio Sánchez Mejías» ${ }^{24}$ que podemos encontrar en Lápidas, y «en realidad, toda la poesía de Gamoneda podría leerse como una historia seguida, llena de intertextualidad y ecos, casi como un solo argumento» ${ }^{25}$. Tampoco es nuevo el recurso tipográfico en la obra anterior de Gamoneda, como puede verse en las combinaciones de versos sueltos junto a poemas de larga extensión y, como bien señala Miguel Casado ${ }^{26}$, en el libro titulado Lápidas podemos ver una inusual movilidad tipográfica donde «el verso, el versículo, las tiradas de prosa, se mezclan hasta coincidir incluso en el mismo texto». El lenguaje habitual de Gamoneda, «lenguaje fuertemente poetizado, ajeno al habla normal, que quiere distanciarse de ella con claridad (...) ${ }^{27} \mathrm{es,}$ asimismo, reconocible en las partes líricas del Libro de los venenos. Las alusiones a la vegetación pueden verse ya en la poesía de Gamoneda («arándanos, aulagas») ${ }^{28}$ y ahora podemos incluso reconocer recurrencias temáticas, como la del atardecer y la tristeza, o la melancolía:

-El atardecer y la tristeza:

Pasaban trenes en la tarde y su tristeza permanece en mí (Lápidas, p. 320).

(G) Vueltos los hombres en sí, entraron en una gran tristeza (GAMONEDA, p. 58).

(G) Atardecía en las terrazas y Alceo bebió lentamente delante de las sombras (GAMONEDA, p. 59).

-La melancolía:

Cruzan y la melancolía entra en los patios (Lápidas, p. 323).

(G) Melancolía es humor frío y seco que alimenta los huesos y el bazo, y es también el nombre de su enfermedad, que trae heces de sangre negra revueltas con hiel y tristeza (GAMONEDA, p. 105).

${ }^{23}$ Prueba de lo cual son las variaciones introducidas a la hora de ofrecer el texto de obras anteriores en la edición de Cátedra (Cf. CASADO, o.c., pp. 9-11).

24 Ibidem, p. 49.

${ }^{25}$ Ibidem, p. 31.

26 Ibidem, p. 48.

27 Ibidem, p. 45.

28 Ibidem, p. 45. 
Y ya en Lápidas hemos asistido a la transformación en poesía de las tiradas en prosa, dando la impresión de ser algo parecido a una premonición de lo que habría de ocurrir en el Libro de los venenos. En palabras del propio Miguel Casado: «Pero son las tiradas de prosa las que presentan mayor interés, especialmente las de la parte tercera por su carácter de "traducción" desde un texto originario más o menos calificable de narrativo; esta prosa, dice Gamoneda, "aparece duramente reconvertida a la especie poemática, de la que quizá no debio salir nunca"» ${ }^{29}$.

En conclusion, hemos analizado sucintamente una serie de características y circunstancias de una obra contemporánea que contiene como sustancia literaria un texto griego traducido por un humanista. Hemos visto cómo la reescritura, la fuerza de las palabras, el singular problema de adscripción a un género literario, la bibliofilia, el juego tipográfico y las necesarias citas explícitas de autores olvidados se mezclan prodigiosamente, a la manera de un todo orgánico, en esta rara auis de nuestras letras recientes. El antiguo texto médico, despojado ahora de sus exigencias científicas, se ha convertido en patrimonio común no sólo del especialista, sino del lector culto. 
Antiguos textos de ciencia convertidos en poesía: Dioscórides y Andrés...

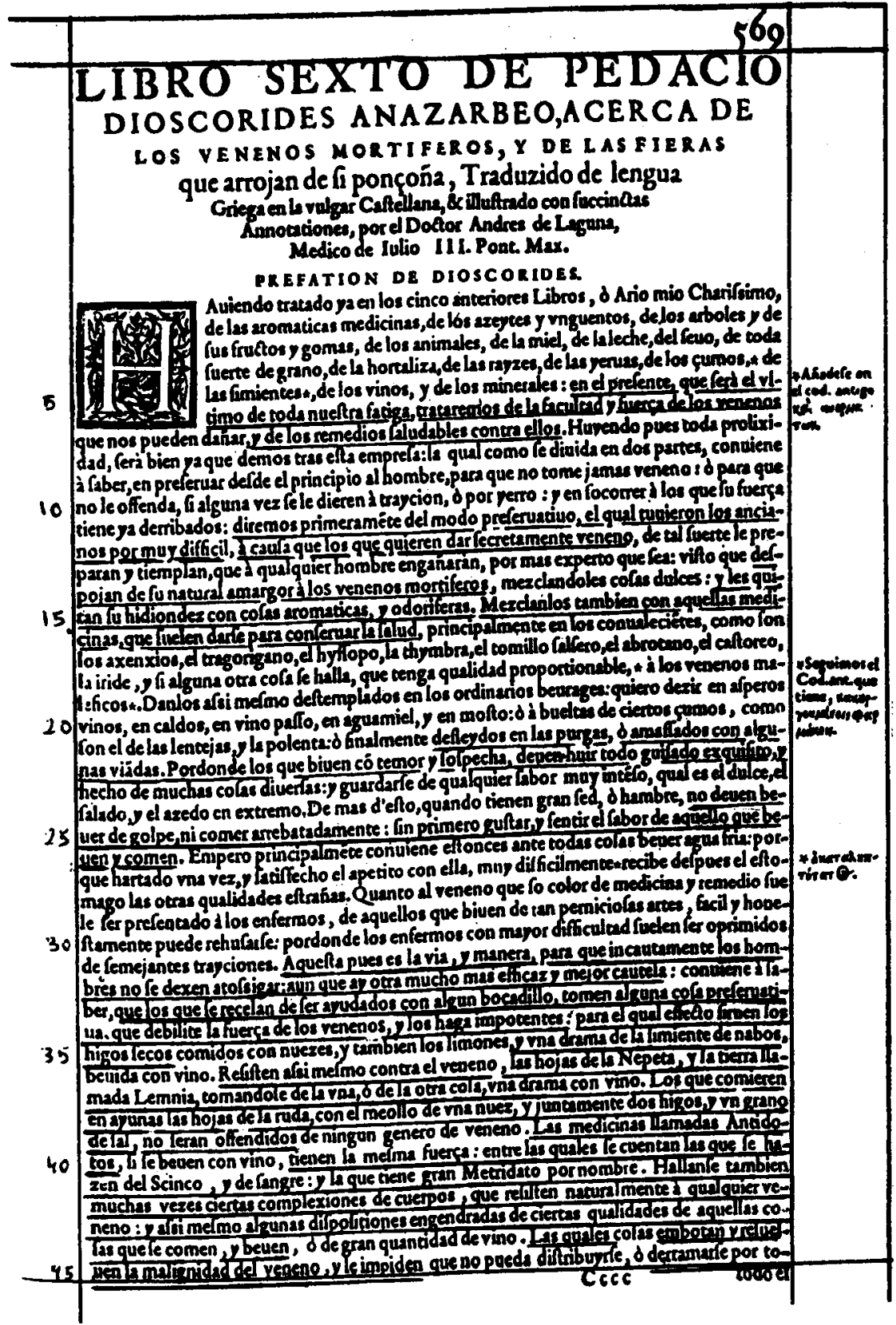

